\title{
VIGILÂNCIA EPIDEMIOLÓGICA: UMA PROPOSTA DE TRANSFORMAÇÃO*
}

\author{
Luiz Jacintbo da Stlva**
}

\begin{abstract}
O Brasil ainda năo construiu um sistema eficiente e confiavel de vigilancia epidemiologgica. A existencia deste sistema e fundamenol para a implanaça de um Sistema Único de Saúde minimamente eficiente. A disponibilidade de meios para a análise de informaçoes permite a organizaça de um sistema razoktrel de vigilancia epidemiologica em tempo relativamente curto. Há necessidade de nfveis de ansalise independentes que possam empreender um trabalho com planejamento a longo prazo e relativamente livre de presabes políicas e economicas. A evoluçalo dos meios de procescamento e anślise de informaçoes e as transformaçbes da clínica e da epidemiologia, particularmente no relacionamento entre as duas, sto pontos fundamentais nas mudanças propostas. A propostra basica e a diseociaça dos nfveis de ańlise dos orgtos da administraçáo direta e descentralizar os sistemas de vigilancia epidemiologica.
\end{abstract}

\section{INTRODUÇÃO}

Não obstante ser uma preocupaçăo antiga em Saúde Pública, a questão da vigilancia epidemiológica ganha contornos diferentes nos dias atuais. $O$ conceito de vigilancia como suporte para medidas policialescas de controle, como a quarentena durante epidemias, a internaçăo compulsória de pacientes com febre amarela ou lepra deve ser descartada. É coisa do passado, não merecendo maiores consideraçóes.

A era pó-revoluça industrial em que vivemos, dominada pela capacidade sempre crescente de manuseio da informaça traz uma nova conceituaçăo de vigilancia epidemiologica. Esta transformaģa determinou mudanças na epidemiologia e na clínica, particularmente na interrelaçăo entre ambas, com reflesos na prática da Saúde Pública. A proposta descentralizadora e municipalizante do Sistema Único de Saúde deverá tambem nortear a implantaça de um sistema de vigilancia epidemiológica.

\footnotetext{
- As colocagbes feitu neace artigo devem muito a excelente reviblo e andibe sobre vigilancia epidemiologica feita por Eliseu A. Faldman em sua rese de doutorndo: "Vigilancta Epidemiologica como Prídea de Saúde Públicun"

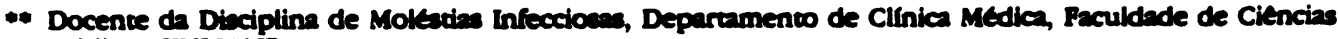
Medicas, UNICNMP.
} 
A evolução do manuseio da informação, com suas conseqüèncias sobre a clínica e a epidemiologia e o modelo de sistema de saúde que almejamos, irão determinar forçosamente o sistema de vigilancia epidemiológica.

Não conseguimos implantar um sistema adequado dentro da conceituação antiga, apesar de alguns sucessos pontuais. Isto não significa que tenhamos que retomar as tentativas anteriores. Refazer a mesma trilha que outros para alcançar uma meta final é um comportamento reacionário. Além disso, por mais adequados que os sistemas de vigilancia epidemiológica de outros países possam parecer, devemos ter em mente que este sistema deve ser uma das bases do Sistema Único de Saúde e, portanto, adequado ao sistema que desejamos e não uma mera réplica de outros países.

Devemos estabelecer uma proposta de desenvolvimento de um sistema de vigilância epidemiológica suficientemente flexível para se adaptar a um meio extremamente mutável, com uma tecnologia de evolução rápida, mas que, principalmente, esteja afinada com as atuais necessidades da epidemiologia como instrumento fundamental das ações de saúde. Devem ser levadas em conta também as mudanças, cada vez mais freqüentes, no perfil dos agravos à saúde. Um sistema de vigilancia epidemiológica não poderá se identificar com grupos de doenças, mas com os agravos à saúde como um todo e suas conseqüências.

Neste artigo, trazemos algumas propostas para a transformação da atual prática de vigilancia epidemiológica, levando em conta alguns fatores considerados fundamentais: a influência da informaçăo na prática médica e, paralelamente, na Saúde Pública, com o conseqüente papel da epidemiologia; a necessidade de agilizar as açőes de saúde, descentralizando não só sua execução mas também a determinação de prioridades e desvincular o processo decisório de estrutura estatal, preservando seu caráter público.

Desde o seu nascedouro, na primeira metade do século passado, que a epidemiologia é, por definiçăo, uma disciplina em que o manuseio da informação é a característica principal. A vigilância epidemiológica é o ramo da epidemiologia que angaria estas informaçóes. Vigilancia epidemiológica não deve ser vista, portanto, como algo separado e distinto da epidemiologia.

Dentro deste contexto, da vigilancia epidemiológica como braço anga- 
riador de informações é que pretendo expor algumas idéias para a organização de um sistema de vigilância epidemiológica para o país.

\section{A INFLUÊNCIA DA INFORMAÇÃO E DA EPIDEMIOLOGIA NA PRÁTICA DA MEdICINA E DA SAÚde PÚBLICA}

É inegável que o volume de informação pertinente à saúde, aliado a facilidade de acesso e manuseio desta informação, está transformando as práticas médica e de saúde pública. Este processo não é exclusivo da Medicina e da Saúde Pública. A quantidade de informação existente sobre os diferentes aspectos das doenças e agravos à saúde é tão grande que pensar em alguém, ou mesmo uma instituição, abarcando o campo, é absurdo, ainda que até há algum tempo não o fosse. Hoje devemos dominar o acesso à informação, buscando meios de poder utilizá-la a qualquer momento. Mesmo assim, dentro de um campo relativamente restrito. $O$ enciclopedismo é contemporaneo da Revolução Francesa.

A Clínica, paradigma da prática médica vigente, cujo limite de abrangência é a capacidade do médico de atender individualmente seus pacientes, começou a sofrer transformaçóes cada vez maiores desde o término da II Guerra Mundial. A necessidade de estender $O$ atendimento médico a segmentos cada vez maiores da população, fenómeno verificado tanto nos países capitalistas como nos países socialistas, aliada à significaçăo crescente da prática médica, criou a necessidade de racionalizar a clínica.

Uma destas transformaçőes, sem dúvida uma das mais importantes, e que diz respeito diretamente à epidemiologia e à vigilancia foi a mudança de horizontes. Até a década de 1950, o horizonte de experiencia do médico não ia muito além dos pacientes que ele havia visto. A introdução de tratamentos mais caros e de maior risco, como a quimioterapia anti-nęoplásica, cirurgias cardiacas, os antimicrobianos mais potentes, para citar apenas alguns exemplos, fez com que o horizonte da experiencia individual se tornasse acanhado, insuficiente para fornecer as informaçőes necessárias.

A busca da racionalizaçăo da clínica, fez com que se recorresse à epidemiologia. Foi o surgimento da epidemiologia clínica. Com o tempo, a clínica foi sendo ampliada a segmentos cada vez maiores, a ponto da Organiza- 
ção Mundial da Saúde, ao adotar o lema de " Saúde para Todos no Ano 2000" , adotar também o modelo da clínica racionalizada, simplificada e estendida a todos. Chegamos, neste final de século, a uma situação em que a racionalização da prática clínica - por racionalização entendo uma prática calcada em procedimentos padronizados - torna-se uma necessidade tanto a nível de países em desenvolvimento como de países industrializados.

A dicotomia entre medicina preventiva e medicina curativa desaparece, as práticas coletivas se fundem com as práticas individuais e se valem destas para atingir metas de saúde pública. Um excelente exemplo é o da cólera.

A cólera é uma doença cujo controle se baseia no diagnóstico e tratamento precoces, tratamento este bem padronizado, fruto de uma racionalização da prática clínica. A ação coletiva de controlar uma doença se baseia no conjunto de ações individuais, que para terem sucesso devem ser adequadamente orquestradas. A prática do clínico que atende a um paciente de cólera não permite grandes variaçōes. Apenas a adesão a um esquema testado fará com que, no conjunto, se consiga manter a letalidade abaixo de 1 por cento. Existe pequena margem para a "experiência individual" de cada clínico.

Para se conseguir esta padronização, foi necessário expandir o horizonte da clínica: este ultrapassou o restrito campo da experiência individual e atingiu o horizonte do ocorrido em grandes conjuntos de pacientes. A maneira de apreender este novo horizonte foi através da epidemiologia.

A relação entre a clínica e a epidemiologia se inverteu, e a experiência epidemiológica passou a determinar a prática clínica. $\mathbf{\Lambda}$ hipertensão é um excelente exemplo. A própria definição de hipertensão é agora uma definição epidemiológica e não mais clínica: hipertensão é o nível de pressão acima do qual existe um risco relativo significativo de desenvolvimento de complicaçöes cardiovasculares. A epidemiologia passa assim de uma disciplina auxiliar da saúde pública, para a disciplina fundamental da assistencia à saúde, determinando as práticas a serem seguidas.

Os conceitos vigentes até há pouco tempo, estabelecidos após a observação de pequeno número de pacientes ou pela somatória de observações isoladas é substituído pela observação controlada de grande número de pacientes. É inaceitável hoje, trabalhar em saúde sem manuseio de informação. 
Não há dúvidas que esta transformação se fez possível, não pelo desenvolvimento dos computadores, mas sim do fácil acesso a eles. $O$ computador de uso pessoal veio tornar possível a análise de informaçóes a qualquer nível. As transformações sofridas pela prática médica e de saúde pública não passaram longe da epidemiologia, muito pelo contrário, a epidemiologia foi e é a disciplina transformadora da prática.

A disponibilidade de programas epidemiológicos e estatísticos de fácil manuseio, abriu as portas da análise epidemiológica, até então restrito a uns poucos iniciados. A análise e difusão das informações em vigilancia, classicamente restritas aos níveis mais centrais, hoje estão ao alcance de qualquer nível, desde que disponha de um mínimo de equipamento. Esta transformação tecnológica ainda em evolução, por si só, obriga à reformulação dos dogmas clássicos da vigilância epidemiológica.

\section{PROPOSTAS PARA UM SISTEMA DE VIGILÂNCLA EPIDEMIOLÓGICA DE ȦMBITO NACIONAL}

Note-se que não me referi à implantação ou construção de um sistema de vigilância epidemiológica, mas sim à organização de um tal sistema. Em primeiro lugar, cabe destacar a importancia da existencia de um tal sistema. Administrar um sistema de saúde sem um adequado banco de informaçōes recentes e confiáveis é algo como tentar conduzir a economia de um país șem indicadores confiáveis.

De passagem, é interessante lembrar que, salvo durante alguns breves períodos, as entidades geradoras das informaçóes economicas no Brasil: a Fundaçăo Getúlio Vargas (FGV) e Fundaçäo Instituto Brasileiro de Geografia e Estatística (IBGE), não obstante amplamente subsidiadas pelo Estado, guardam um significativo grau de independencia em relaçăo ao Governo.

Esta é uma das colocaçôes fundamentais: a necessidade de haver um nível de análise e de orientaçăo da sistemática de coleta de informaçóes que seja independente. A funçăo de um nível de análise năo é exclusivamente técnica: reveste-se de uma importancia política muito grande. $O$ estabelecimento das prioridades de açăo na saúde devem ser determinadas por uma 
adequada análise dos indicadores e outras informações obtidas através de um sistema de vigilância epidemiológica.

Grande demais para se arriscar sua manipulação por estruturas facilmente mutáveis e pressionáveis da área de saúde, como Secretarias e Ministérios, a responsabilidade da obtenção e análise das informaçōes em vigilância epidemiológica deve ser protegida. A autonomia deve ser tanto política como financeira. Ainda que não seja possível uma autonomia total, algo como a situação de algumas instituições seria desejável, as universidades paulistas, a Fundação Padre Anchieta ou a FAPESP, por exemplo, se aproximam muito daquilo a que me refiro.

A facilidade de manipulação das informações em todos os níveis, assim como a diversidade dos diferentés perfis epidemiológicos do país tornam necessária a organização de um sistema bastante descentralizado. Não há necessidade de se replicar a mesma estrutura em todas as unidades da federação, tampouco de se tornar obrigatória a instituição de sistemas de vigilância epidemiológica a nível de todas as Secretarias de Saúde, estaduais e municipais. Apenas Secretarias de grande porte suportam um sistema de vigilância epidemiológica adequado.

A tradição burocrática brasileira tem feito com que sempre que se busca implantar sistemas de vigilância epidemiológica, se inicie o processo por normas, leis e decretos, impondo verticalmente, de cima para baixo, uma série de procedimentos que visam permitir a algum organismo central, o acúmulo de dados sobre diferentes doenças e estruturando este sistema nos órgãos oficiais de saúde. Até recentemente, a não descentralizaçāo do sistema de saúde, em que o nível mais periférico era o estadual, com a conseqüente centralização do poder decisório, assim como a possibilidade de se organizar açőes de Saúde Pública razoavelmente eficazes mesmo na ausencia de informações confiáveis, fez com que a inexistência de um adequado sistema de informações de saúde (inclua-se aqui a vigilancia epidemiológica) fosse tolerada. Hoje, pelos motivos analisados acima, como também pela descentralização gradativa do poder decisório em saúde, esta situação não está sendo mais tolerada. A necessidade da organizaçăo de um sistema de vigilancia epidemiológica que dé o necessário apoio à implantação de um Sistema Único de Saúde minimamente eficiente e democrático se torna imperiosa. 
Um sistema destes implica numa adequada estrutura laboratorial de apoio, assim como uma estrutura de análise de informações. Muitas vezes uma Universidade ou uma entidade paraestatal pode se desencumbir melhor da tarefa do que uma Secretaria de Saúde ainda incipiente, forçada a montar um sistema de vigilancia epidemiológica devido a existéncia de algum decreto planaltino.

Em resumo, o que pretendo mostrar é que não será possível dispor de um adequado sistema de vigilancia epidemiológica através da excessiva regulamentação, nem da disputa. A situação do cólera é exemplo ilustrativo: as informações disponíveis são coletadas pela imprensa. O Ministério da Saúde polemiza com as Secretarias estaduais e municipais, seja pelo número de casos existentes, seja pela natureza de uma bactéria isolada dos esgotos. Normas e regulamentos em vigilancia epidemiológica não podem ser determinados, devem ser fruto de consenso.

Criou-se entre nós o conceito de que a normatização em vigilancia epidemiológica deve ser centralizada. Talvez isto fosse possível ou necessário no passado. Não é mais. A difusão da informação, a facilidade do seu manuseio, particularmente de sua transmissão a qualquer distáncia obriga o exercício das tomadas de decisão consensuais.

A democratização da normatização técnica, a desvinculação dos níveis de análise dos órgãos da administraçăo direta e a flexibilidade na organização do sistema săo os princípios básicos que devem nortear a organizaçăo da vigilancia epidemiológica no país. O que se dispóe hoje é caótico. As flutuaçōes salariais no serviço público e as mudanças freqüentes das políticas de investimento em saúde impedem o surgimento de uma geração de epidemiologistas que possam levar a cabo esta tarefa.

Da mesma maneira, o sucateamento dos laboratórios de saúde pública contribuiu para impedir a existencia de um sistema nacional de vigilancia epidemiológica. Outro aspecto é a excessiva vinculaçăo do conceito de vigilância epidemiológica ao controle de doenças transmissíveis. A coleta e análise de informaçōes epidemiologicamente relevantes não deve se restringir às doenças transmissíveis.

A organização de um sistema de Ambito nacional é fundamental para a 
condução de uma política decente de saúde. Devemos nos livrar rapidamente da visão central e passar a organizar um sistema em bases modernas e democráticas. A iniciativa deve partir dos colegiados de Secretarias Estaduais e Municipais, que deverão organizar sistemas regionais a serem interligados num sistema nacional. Não há necessidade de excessiva uniformização, este é um conceito ultrapassado, que deve ser enterrado junto com os milhares de decretos, normas e regulamentos federais referentes à vigilancia epidemiológica. 